\title{
Functional morphological study of the choana in different bird species
}

\author{
Fatma A. Mahmoud ${ }^{1 *}$, Ali G. Gadel-Rab² and Nahed A. Shawki ${ }^{1}$
}

\begin{abstract}
Background: The anatomical information about the structure of the choana is lacking in literature, and its role in the olfactory and feeding mechanism is still unknown

Results: The present study discusses the adaptation of choana to cranial kinesis during feeding process in different bird species: kestrel, common moorhen, and hoopoe. Kestrel possesses a kinetic skull while the hoopoe and common moorhen have kinetic one; however, the common moorhen skull seems highly kinetic more than that of the hoopoe that properly effect on the choanal epithelium. The choana of kestrel and hoopoe are lined by pseudostratified ciliated columnar epithelium, while choana of common moorhen have transitional epithelium beside pseudostratified ciliated columnar epithelium. The choana epithelium of each bird species provides with simple alveolar glands and numerous goblet cells. In kestrel and hoopoe, the secretion products of choanal glands contain neutral and sulfated mucin, while in the common moorhen, these glands secret neutral and carboxylate mucopolysaccharides.
\end{abstract}

Conclusion: The choana of the three studied bird species apparents adaptation to the olfaction process but also affects the movement of skeletal elements of the skull during the feeding process

Keywords: Choana, Cranial, Kinesis, Bird, Feeding process

\section{Background}

Birds have variation in the form and function of their feeding system which are amenable to comparative analysis because they represent modifications of the same basic structure of this apparatus among different species without a doubt that reflected the success of birds to survival and occupy a wide range of habitats. Many of the literature has studied the avian feeding system (Jackowiak \& Godynicki, 2004; Mahmoud, Shawki, \& Wahba, 2009; El-Bakary, 2011, 2012; AlZahaby \& Elsheikh, 2014; Erdogan \& Iwasaki, 2014; and Shah \& Aziz, 2014; Gadel-Rab, Shawki, \& Saber, 2017), but still the feeding mechanics and functional morphological information about most bird species remain poorly understood.

The roof of buccal cavity is considered as a part of feeding system and was given little attention in literature. It is interesting to state that only Shawki, Abdeen, and Mahmoud (2016) gave a clear description of the roof of buccal cavity of the kestrel and discussed its

\footnotetext{
* Correspondence: m_f11_7@yahoo.com

${ }^{1}$ Department of Zoology, Faculty of Science, Assiut University, Assiut, Egypt Full list of author information is available at the end of the article
}

role in the feeding mechanism. Mahmoud, Gad-Rab, and Shawki (2017) pointed out the effect of different feeding behaviors on the lining epithelium of the roof of buccal cavity of two bird species.

The feeding and sensory systems are considered integrating systems and reflect a general historical trend of increasing cephalization in vertebrate evolution (Schwenk, 2000). The avian olfactory system consists of the choana which appears in birds and reptiles related to the incomplete secondary palate, through which the nasal and oral cavities communicate with each other (Kent \& Carr, 2001). The anatomical information about the structure of the choana is lacking in literature, and its role in the olfactory and feeding mechanism is still unknown.

Thus, the present study gives attention to the functional morphological structure of the choana in three different bird species to exhibit the adaptation of the choana to the feeding process.

The selected bird species are kestrel, hoopoe, and common moorhen that belong to different avian's orders: Falconiformes, Bucerotiformes, and Gruiformes, respectively, each of them have own feeding behavior. 


\section{Methods}

The specimens of three bird species in the present study were collected from Abou-Rawash area of Egypt and brought alive to the comparative anatomy of vertebrate lab. The specimens were anesthetized by ether then dissected under wild stereomicroscope to separate the head from the rest of the body. Some specimens were carefully investigated by wild stereomicroscope to clarify the anatomical features of roof of mouth; the skull the was prepared; and then photos were photographed by using a digital camera. Some specimens were fixed in $10 \%$ neutral formalin for 3 days and prepared to paraffin embedding. Tissues were sectioned at $7 \mu \mathrm{m}$ and stained with Hematoxylin and Eosin, Masson's trichrome, Bromophenol blue, PAS and PAS-Alcian blue (Bancroft \& Stevens, 1996).

\section{Results}

The buccal cavity of the three studied bird species is bounded externally by their beak while internally, it can be distinguished into the floor of mouth, which includes the tongue, and the roof of mouth which contains two regions: the palate and pharyngeal region. The palate region (PL) occupies the choana that faces the glottis within the tongue. The choana $(\mathrm{C})$ of each studied bird species exhibits different shape; in kestrel, it appears to be formed from two parts, a short narrow anterior part and long-wide posterior one separated by a constriction (Fig. 1). In common moorhen, the choana is formed from two equal parts, an anterior tapering part and a

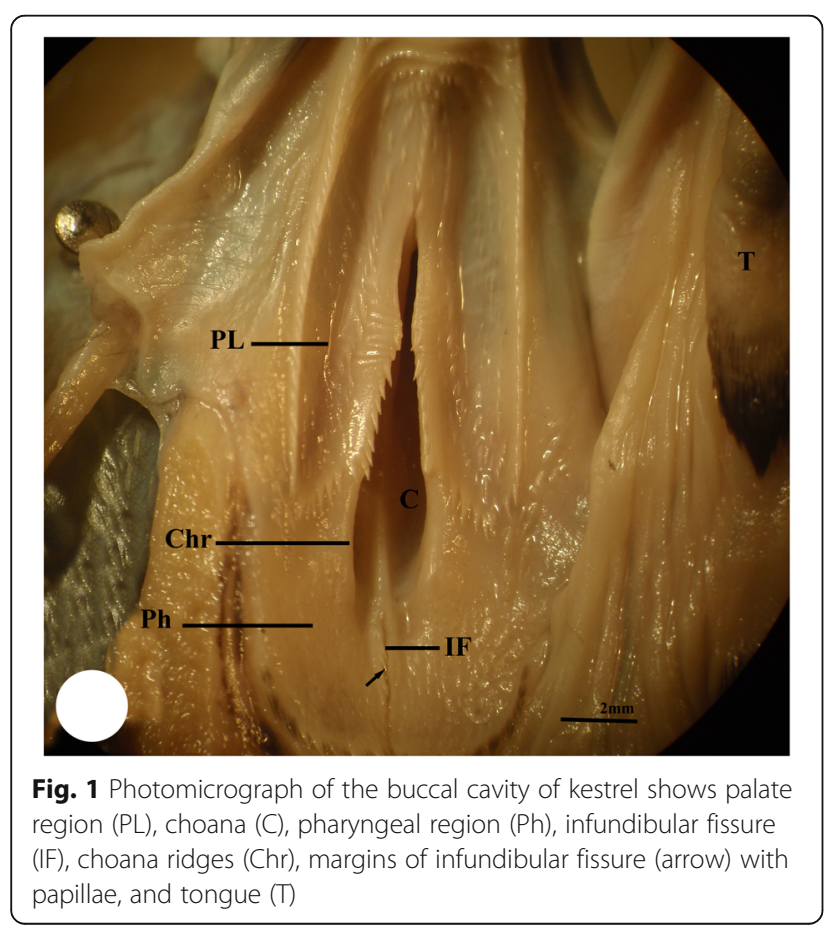

posterior wide one (Fig. 2). Meanwhile, the choana of the hoopoe has pear-shape with posterior wide half and slightly anterior narrow one (Fig. 3). The pharyngeal region $(\mathrm{Ph})$ of kestrel and common moorhen is situated posterior to the palatine wing which is not distinguished in the hoopoe. The pharyngeal region in the three studied bird species incubates the oval-shaped fissure which is known as the infundibular fissure (IF). In the present study, the infundibular fissure of the kestrel and hoopoe is located posterior to the choana ridges $(\mathrm{Chr})$, while in the common moorhen, it lies within the choana ridges. The margins of infundibular fissure of the kestrel carry a longitudinal row of posteriorly directed papillae, whereas these

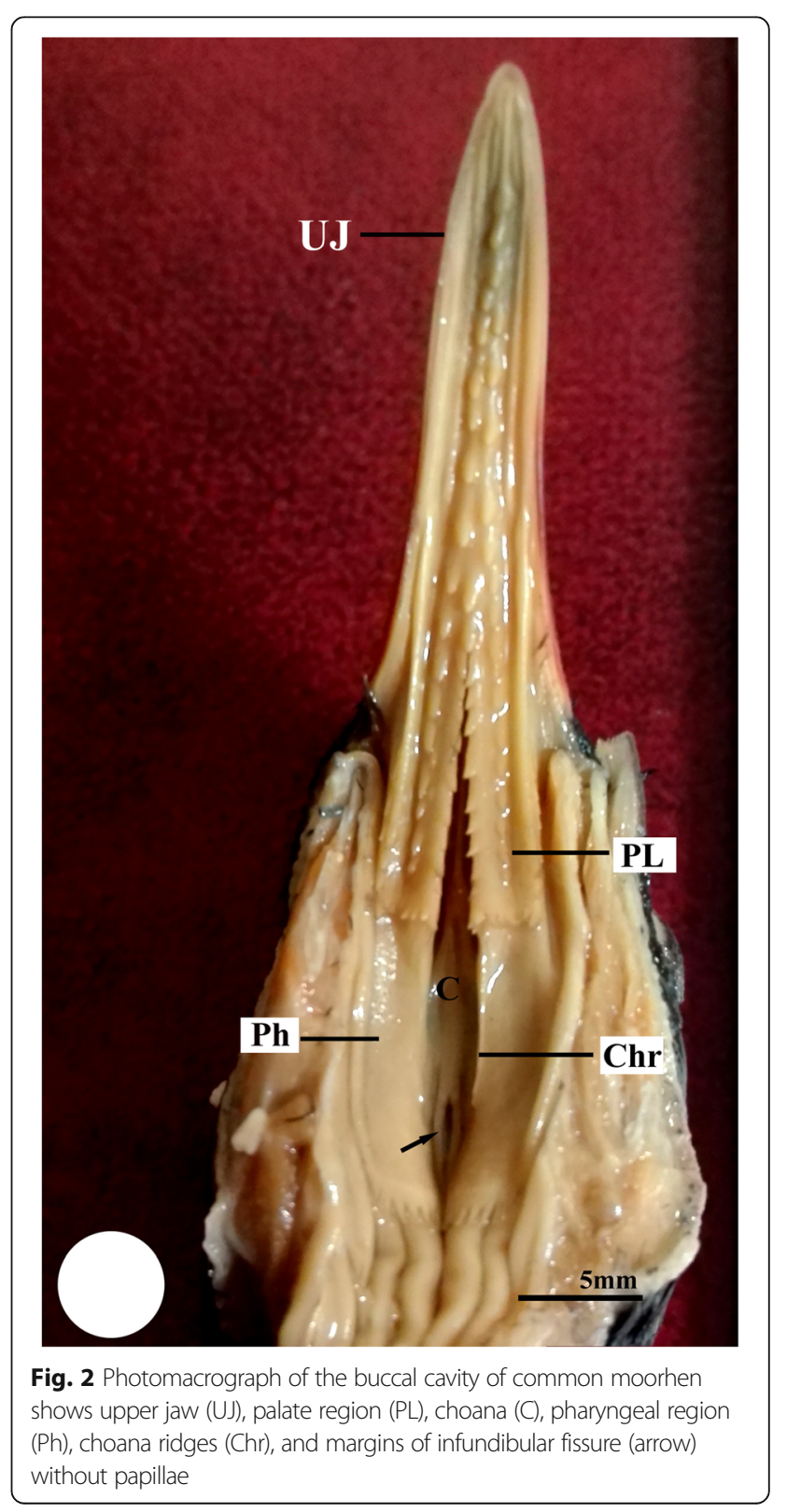




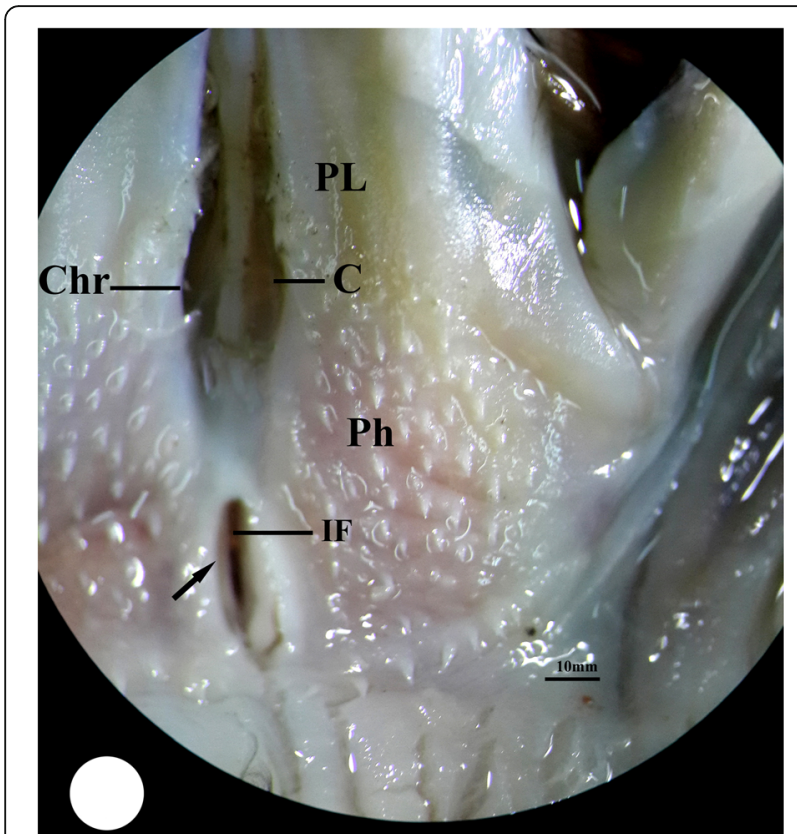

Fig. 3 Photomicrograph of the buccal cavity of hoopoe shows palate region $(\mathrm{PL})$, choana $(\mathrm{C})$, pharyngeal region $(\mathrm{Ph})$, infundibular fissure (IF), choana ridges (Chr), and margins of infundibular fissure (arrow) with papillae

papillae disappear in the case of hoopoe and the common moorhen (Figs. 1, 2, and 3).

The roof of the mouth is supported by the palatine bone (Os palatinum) which exhibits anatomical variation in the three studied bird species. The palatine bone have paired anterior portion (the maxillary process of the palatine bone, Map) which appears thick and narrow in the kestrel and broader in the hoopoe (Figs. 4 and 5), while in the common moorhen, it is long, thin, and dorsomedially curved. Moreover, this portion is fused laterally with the posterior portion of the maxillae "upper jaw, UJ" through the maxillopalatine process (Fig. 6 and 7). Meanwhile, in the kestrel and hoopoe, this process is completely fused with the ventral surface of the upper jaw (UJ) (Figs. 8, and 9).

Dorsally, the vomer bone is located between the anterior portion of palatine and extends posteriorly to fuse with the parasphenoid bone. In the kestrel, the vomer bone has club shape with rounded head which fuse anteriorly with maxillopalatine process (MP), and extends posteriorly as rod-shape to fuse with the parasphenoid bone (Fig. 8). Meanwhile, in the common moorhen, the vomer bone initiates as narrow unpaired bone, then forks posteriorly towards the parasphenoid bone (Figs. 6 and 7), whereas in the hoopoe, the vomer bone is absent and replaced by a longitudinal ribbon of collagenous connective tissue which extends posteriorly cross the ventromedial surface of the parasphenoid bone (Fig. 9).

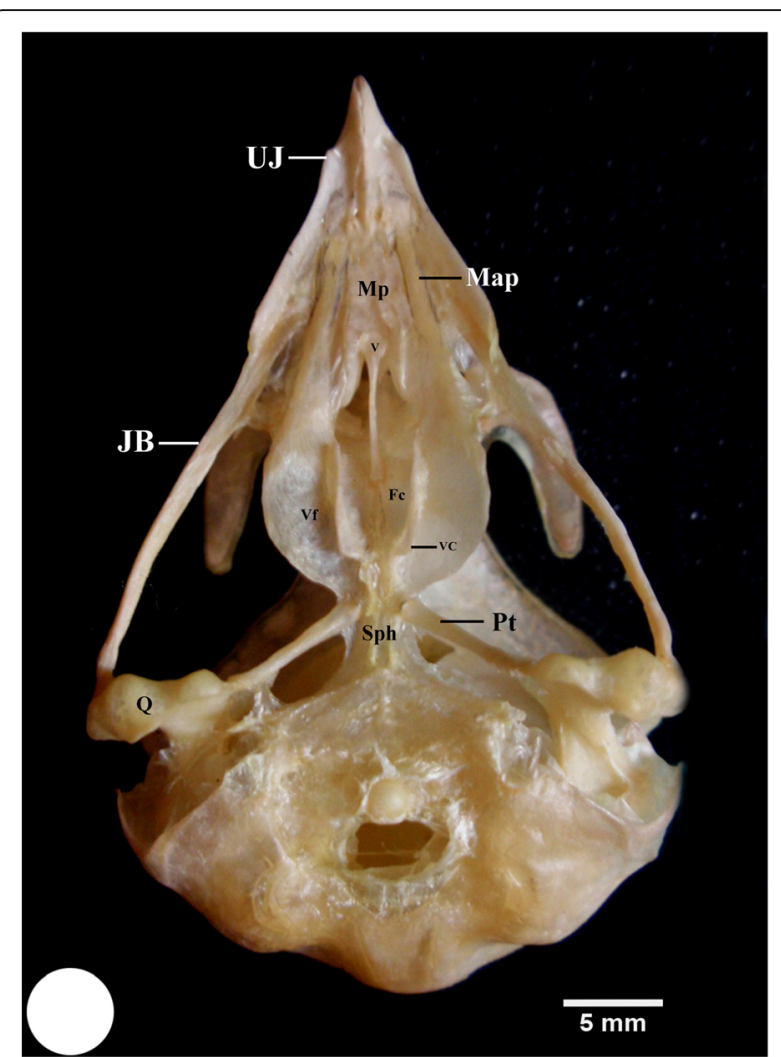

Fig. 4 Photomacrograph of ventral surface of skull of kestrel shows upper jaw $(U J)$, Jugal bar (JB), the maxillary process of the palatine bone (Map), maxillopalatine process (MP), vomer bone (V), choana fossa (Fc), medial crest (arrow), ventral crest $(V c)$, ventral fossa $(V f)$, Pterygoid (Pt), and parasphenoid (Sph)

Posteriorly, the palatine bone broads to form the pars lateralis which contains the ventral fossa. This fossa appears deeper in the common moorhen than that of the kestrel, while in the hoopoe, it appears shallow (Figs. 7, 8 , and 9). The pars lateralis possesses medial and ventral crest which enclose the choana fossa between them. The choana fossa is narrow and shallow in the kestrel, broad and slightly deep in the common moorhen, and narrow and deep in the hoopoe (Figs. 7, 8, and 9).

Moreover, the kestrel and common moorhen have paired medial crest (Figs. 7 and 8) that is absent in the case of hoopoe and replaced by fibrous connective tissue (Fig. 9). The ventral crest that forms the lateral wall of the choana protrudes ventrally in the kestrel and the common moorhen more than in the hoopoe.

The histological investigation of the roof of the mouth of three studied bird species revealed that the roof is covered by stratified squamous epithelium with variation in keratinzation; in the kestrel and the common moorhen, the lining epithelium of the roof is keratinized (Figs. 10 and 11), while the roof of the hoopoe is covered by non-keratinized epithelium with appearance of keratinization on the palatine papillae (Fig. 12). However, 


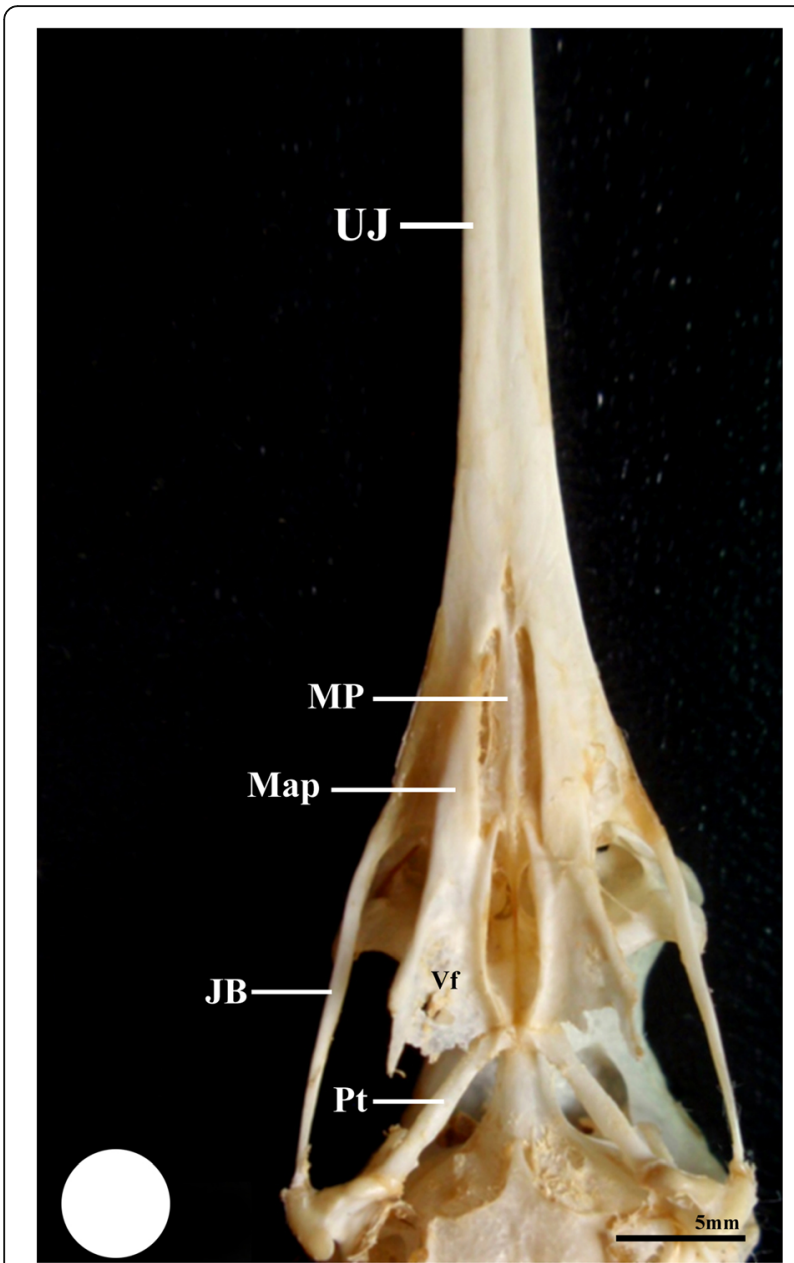

Fig. 5 Photomacrograph of ventral surface of skull of hoopoe shows upper jaw (UJ), Jugal bar (JB), the maxillary process of the palatine bone (Map), maxillopalatine process (MP), ventral fossa (Vf), Pterygoid (Pt), and parasphenoid (Sph)

in the studied bird species, the epithelium layer of the roof lines the choana extends dorsally and changes gradually from stratified squamous epithelium into pseudostratified ciliated columnar epithelium (Figs. 10, 11, 12, and 13). Moreover, in the common moorhen, the dorsomedial surface of choana is covered by transitional epithelium (Fig. 13b).

The simple alveolar gland and goblet cells are distributed within the lining epithelium of the choana of all species analyzed. In the common moorhen, compound-branched alveolar glands were observed embedding dorso-medially within the epithelium of the chaona (Fig. 13a).

In all investigated species, the glandular cells of the choanal gland are strongly reacted with PAS indicating the presence of neutral mucopolysaccharides (Fig. 14b, c) and give positive reaction with PAS-Alcian blue that indicate the presence of neutral and acid mucopolysaccharides (Fig. 14a).

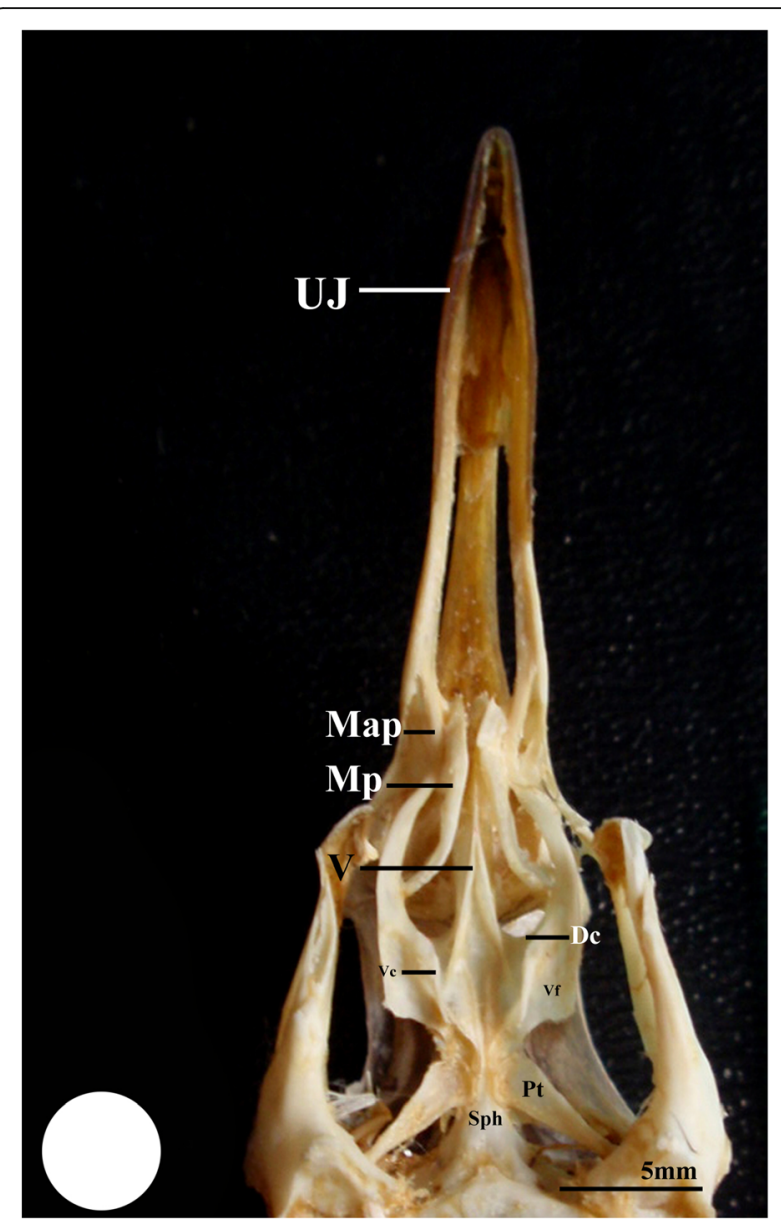

Fig. 6 Photograph of ventral surface of skull of common moorhen shows upper jaw $(U \mathrm{U})$, the maxillary process of the palatine bone (Map), maxillopalatineprocess (MP), vomer bone (V), choana fossa $(\mathrm{Fc})$, ventral crest $(\mathrm{Vc})$, dorsal crest $(\mathrm{Dc})$, ventral fossa $(\mathrm{Vf})$, Pterygoid (Pt), and parasphenoid (Sph)

The glandular cells of the choanal glands of kestrel and the hoopoe exhibited a slight positive staining affinity with Alcian-blue PH 2(Fig. 15a, c), while moderate in the common moorhen (Fig. 15b). This indicates the presence of carboxylate mucopolysaccharides. In kestrel and hoopoe, the glandular cells of the choanal glands give deep-bluish color with Alcian-blue PH1 (Fig. 15d, f) which mean the presence of sulfated mucopolysaccharides. In the common moorhen, the glandular cells within the epithelium covering the dorso-medial surface of choana give deep blue color with Alcian-blue PH1 while that covering the lateral surface give faint blue color (Fig. 15e, g).

Moreover, in kestrel and hoopoe, the choanal glands showed moderate reaction with mercuric bromophenol blue (Fig. 14d, f) indicating the presence of protein secretory materials, while in the common moorhen, the choanal glands gives slightly react with mercuric bromophenol blue (Fig. 14e). 


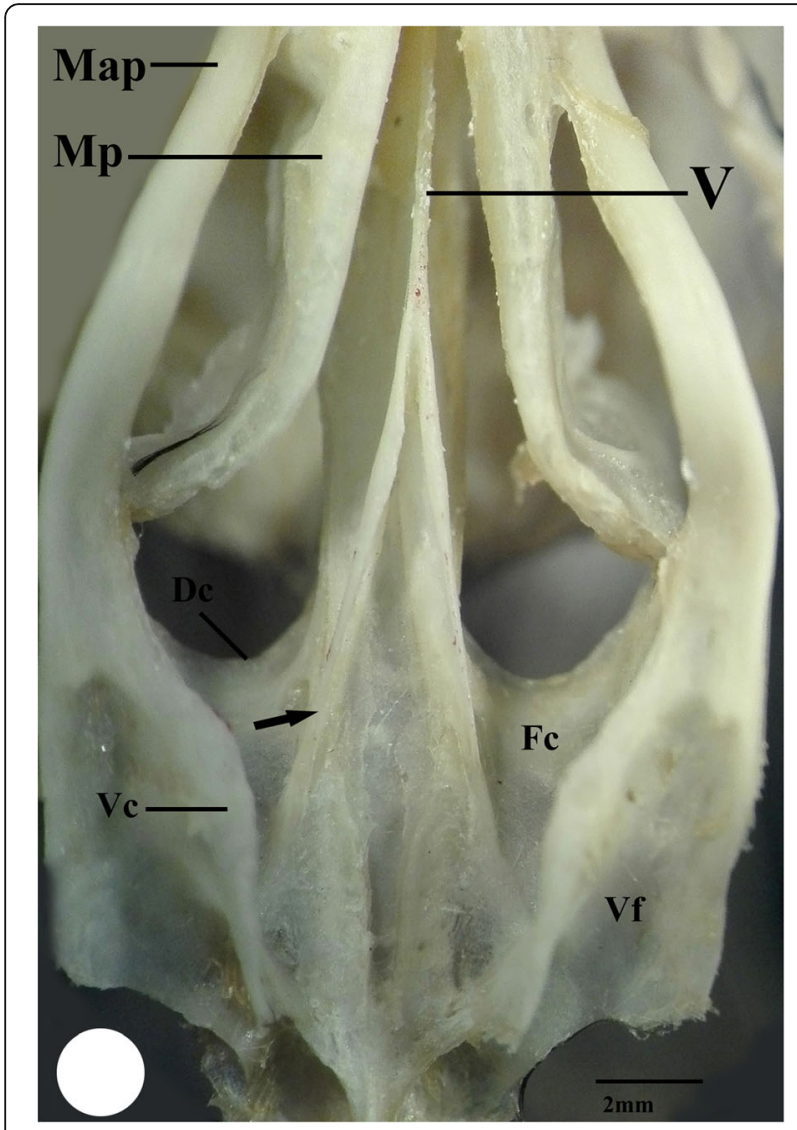

Fig. 7 High magnification of ventral surface of skull of common moorhen shows the maxillary process of the palatine bone (Map), maxillopalatine process (MP), vomer bone $(\mathrm{V})$, choana fossa (Fc), medial crest (arrow), ventral crest (Vc), and ventral fossa (Vf)

\section{Discussion}

The kestrel, common moorhen, and hoopoe are three different bird species with different feeding behaviors: kestrel is prey-predator bird which possesses hard curved beaks to cut their prey while the hoopoe and common moorhen are probing birds that catch their prey by different strategies. Shawki and Ismail (2006) and Mahmoud et al. (2009) mentioned the functional morphological structure of the lingual apparatus of the common moorhen and kestrel respectively and confirmed that these bird species mainly rely on their lingual apparatus in feeding process, while the hoopoe depends on the jaw apparatus in manipulating their prey than its tongue (Gadel-Rab, Shawki, \& Saber, 2012) which agree with those mentioned by Rawal (1968) who concluded that the long arms of hoopoe's bill confer greater advantage in thrusting the bill into soil.

The cranial kinesis is an important character of the feeding behavior of birds (Bout \& Zweers, 2001). The kestrel, hoopoe, and common moorhen are prokinetic birds like most bird species, in which the bending

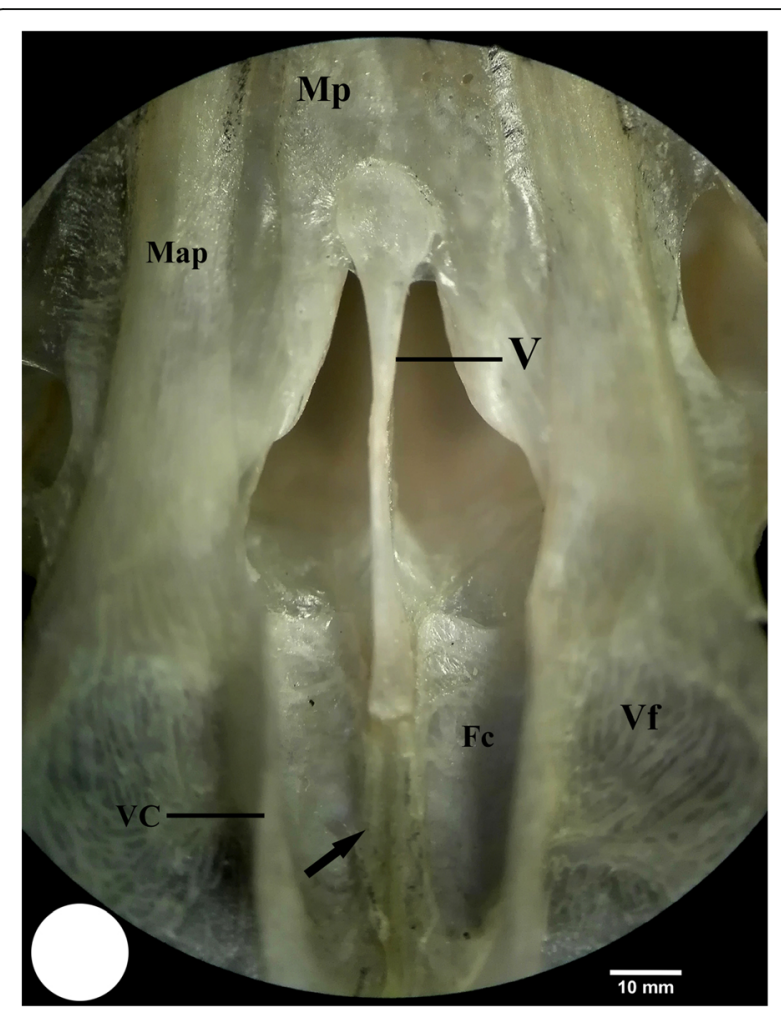

Fig. 8 High magnification of ventral surface of skull of kestrel shows the maxillary process of the palatine bone (Map), maxillopalatine process (MP), vomer bone $(\mathrm{V})$, choana fossa (Fc), medial crest (arrow), ventral crest (Vc), and ventral fossa (Vf)

zone is situated at the nasal-frontal hinge that allows the movement of the upper jaw up/down relative to the skull.

Mahmoud, Shawki, and Abdeen (2017) clarified that there is no flexible zone appearing at the nasal-frontal hinge in the kestrel's skull. In the hoopoe, this hinge is movable that confirmed practically during the skull preparation; also in the common moorhen, the upper jaw can depress downward relative to skull. The movement of the upper jaw (depression) occurs as resulting of the contraction of pterygoid muscle complex of each bird species. The pterygoid muscles are originated from the palatine bone "pars lateralis" and insert on the lower jaw "posterior portion of the mandible". The contraction of this muscle pulls the palatine bone backward, thereby depressing the upper jaw, as well as, adducting the mandible by elevating the anterior portion of mandible that leads to closing the beak. Physically, the naso-frontal hinge determines the ability of the gliding movement of the palatine bone beside its shape and position. The skull of kestrel have immovable naso-frontal hinge; this leads to the mechanical force which is produced during the contraction of the pterygoid muscle closing the mandible quickly to produce a strong bit force; this result agree with those mentioned by Mahmoud et al. (2017). 


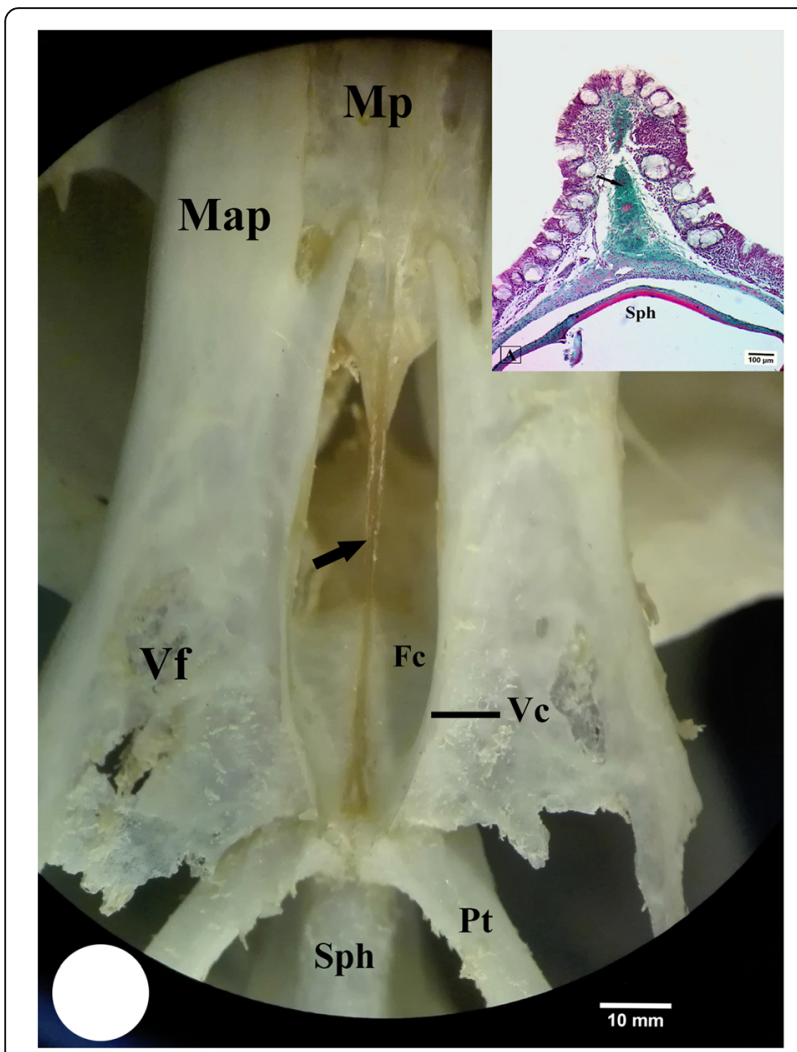

Fig. 9 High magnification of ventral surface of skull of hoopoe shows the maxillary process of the palatine bone (Map), maxillopalatine process (MP), vomer bone (arrow) is absent and replaced by a longitudinal ribbon of collagenous connective tissue, choana fossa (Fc), ventral crest (Vc), ventral fossa (Vf), Pterygoid (Pt), and parasphenoid (Sph). Upper right, photomicrograph of a transverse section of roof of hoopoe shows the collagenous connective tissue. (Masson's Trichrome)

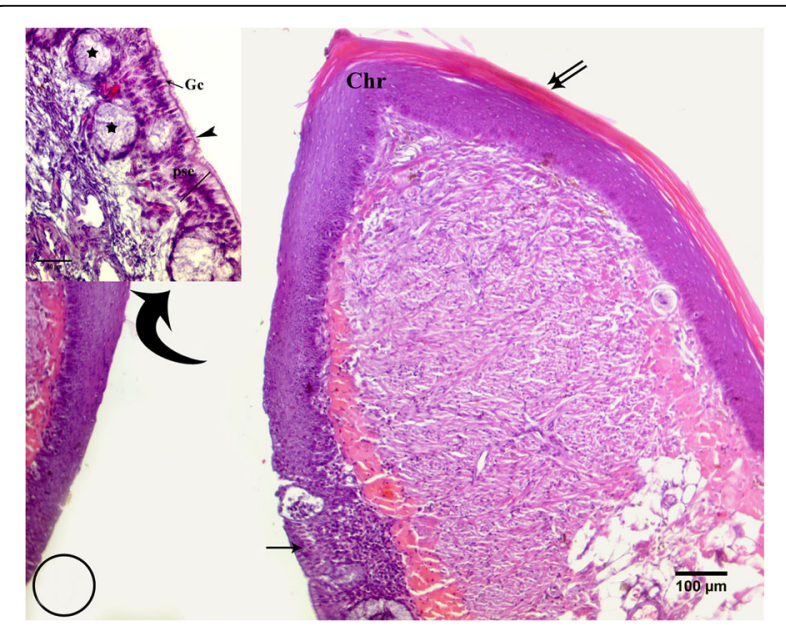

Fig. 10 Photomicrograph of a transverse section of kestrel shows the epithelium roof is keratinized (double arrows) which covers the choanal ridges (Chr), then extends dorsally and changes gradually into pseudostratified ciliated columnar epithelium (arrow). Upper left shows pseudostratified columnar epithelium (Psc) with cilia (head arrow), goblet cell (Gc), and simple alveolar gland (star). (H\&E)

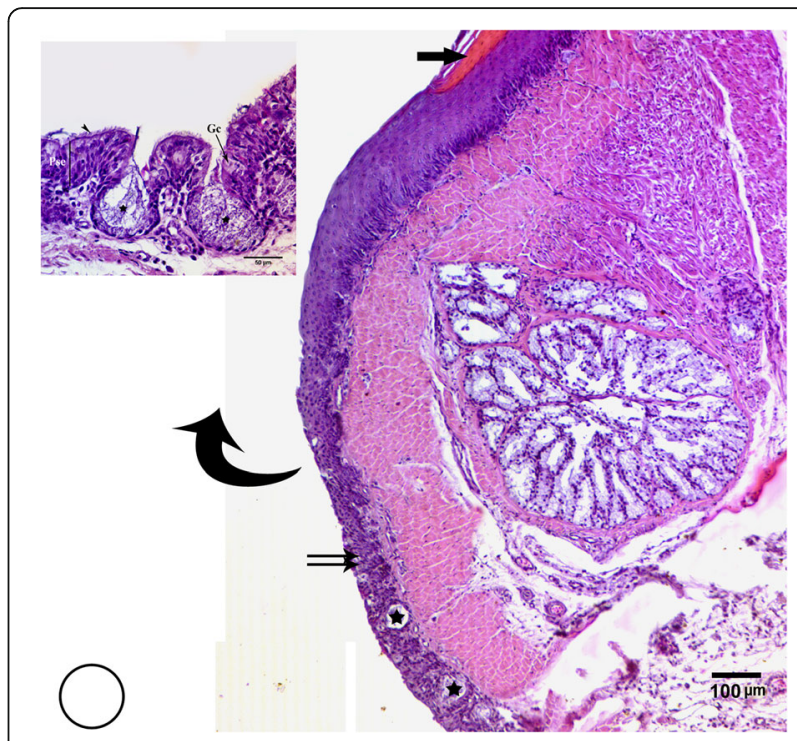

Fig. 11 Photomicrograph of a transverse section of common moorhen shows the epithelium roof is keratinized (arrow) then extends dorsally and changes gradually into pseudostratified ciliated columnar epithelium (double arrows) with simple alveolar gland (star). Upper left shows pseudostratified columnar epithelium (Psc) with cilia (head arrow), goblet cell (Gc) and simple alveolar gland (star). (H\&E)

Meanwhile, in hoopoe and the common moorhen, the movable naso-frontal hinge gives flexibility for depression of the upper jaw by pulling the palatine bone during the contraction of the pterygoid muscle. During depression of upper jaw in the common moorhen, the force transferred to curve the anterior portion of the palatine bone "maxillary process of the palatine bone". This force enables bird to widen the choana. Morphologically, widening of choana

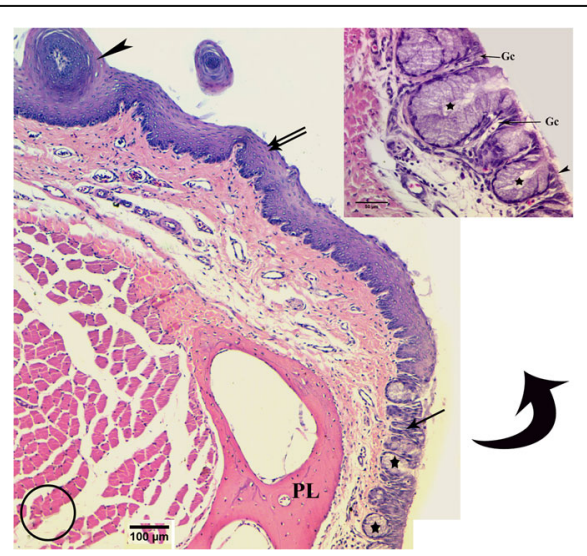

Fig. 12 Photomicrograph of a transverse section of hoopoe shows the epithelium roof is non-keratinized (double arrows), appears only to cover the papillae (head arrow), then changes gradually into pseudostratified ciliated columnar epithelium (arrow) with simple alveolar gland (star). Upper right shows goblet cells (Gc) within pseudostratified ciliated columnar epithelium (head arrow) and simple alveolar gland (star). (H\&E) 


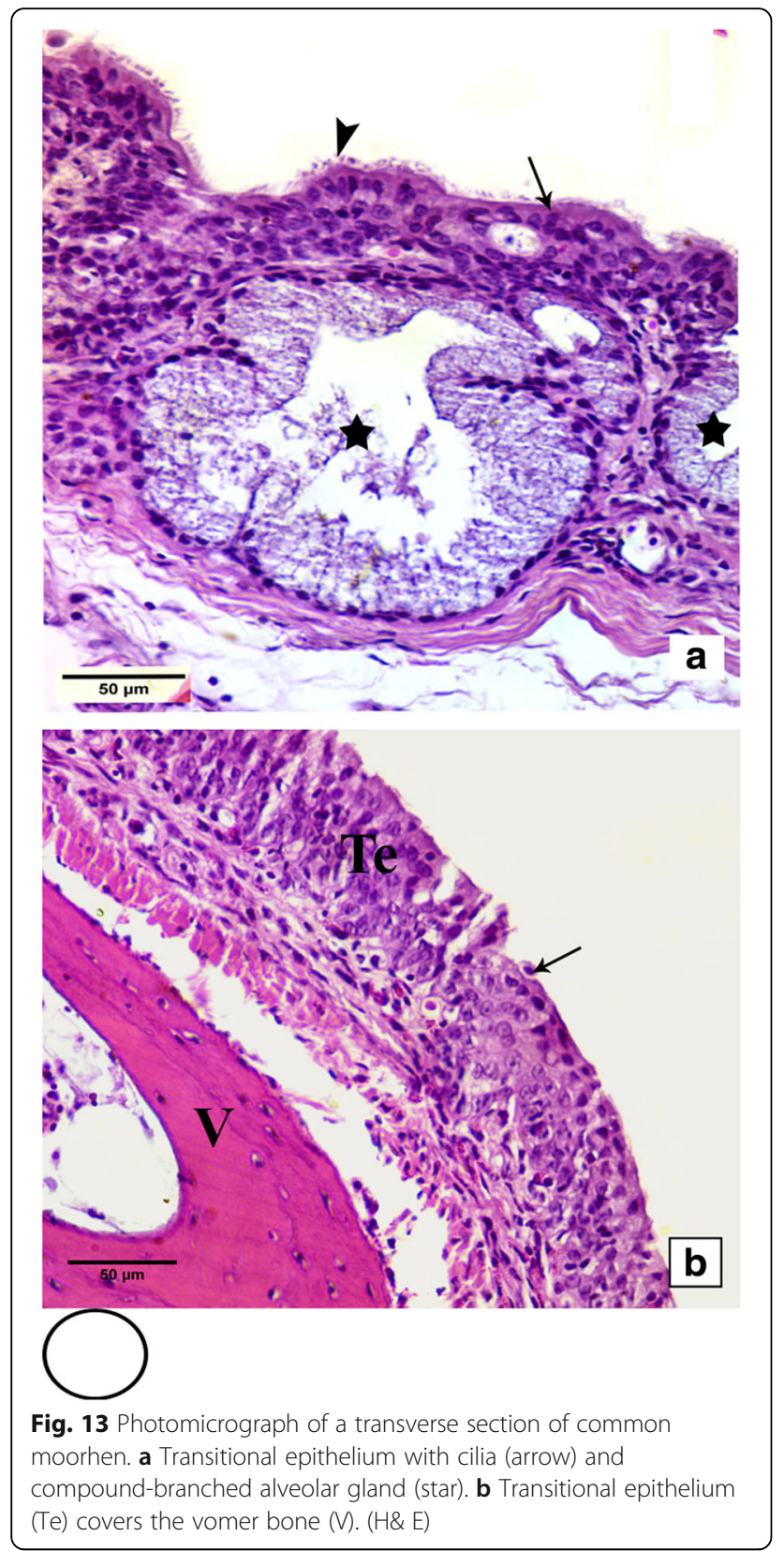

may lead to increase air-flow that drain to the buccal cavity during closing of the mouth after catching prey or may be related to the uptake of large food items. In the hoopoe, the anatomical structure of the palatine bone maxillary process of the palatine bone is none allowable to change the diameter of choana. In fact, the hoopoe catches small insects and worms in no need to change the diameter of choana like that of kestrel which feeds on small items cutting before by their beak.

However, the morphological analysis of choana of these bird species suggests that the ability of movement of upper jaw relative to skull (cranial kinesis) affects the type

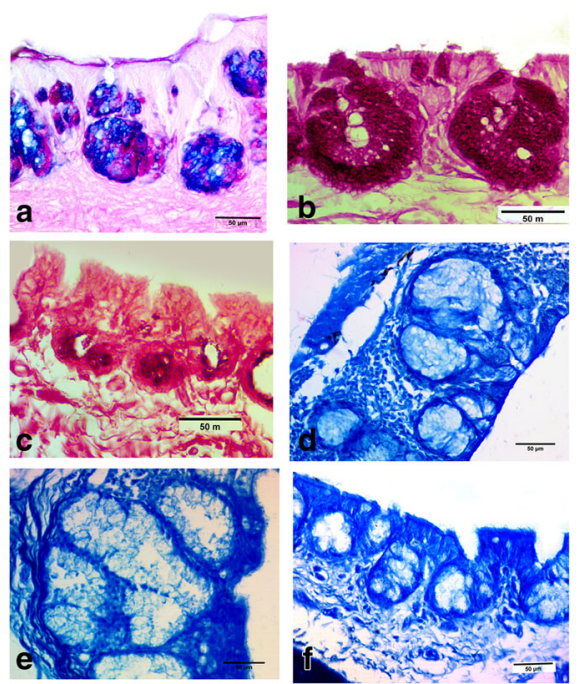

Fig. 14 Photomicrograph of a transverse section of choanal gland, a in kestrel with PAS-Alcian blue, $\mathbf{b}$ in hoopoe with PAS, $\mathbf{c}$ in common moorhen with PAS, $\mathbf{d}$ in kestrel with bromophenel blue, e in common moorhen with bromophenel blue, and $\mathbf{f}$ in hoopoe with bromophenel blue

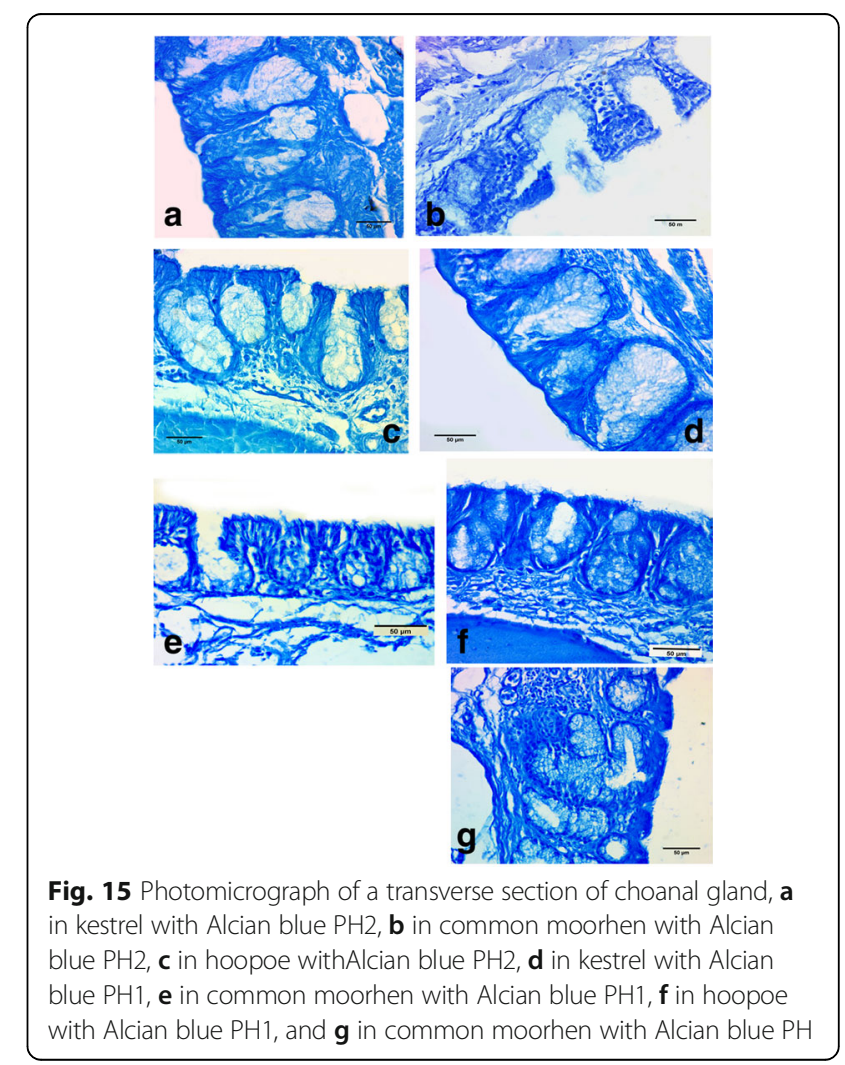


of epithelium that lining the choana. The choana of kestrel and hoopoe is lined by pseudostratified ciliated columnar epithelium. This type of epithelium usually placed within the nasal passages of birds (Bang \& Wenzel, 1995) and some part of respiratory system of other animals (Junqueira \& Carneiro, 1980) formed the mucosa of the olfactory and respiratory tracts. The presence of pseudostratified ciliated columnar epithelium within the choana in all studied bird species may help in increasing the efficiency of smell in these bird species. In addition, in the common moorhen, there is another type of epithelium beside the pseudostratified ciliated columnar epithelium, transitional epithelium type which lining the dorso-medial surface of choana. This surface of choana is more exposed to the mechanical forces during the movement of upper jaw explaining the presence of this type of epithelium in this region. The transitional epithelium has stretching ability during exposure to any pressure, if it is external (food items) or internal (mechanical performance of the feeding apparatus) pressure.

Moreover, the epithelium of choana in the three studied bird species provides with simple alveolar glands and numerous goblet cells which lack in most bird species (Bang \& Wenzel, 1995). In kestrel and hoopoe, the secretion products of glands contain neutral and sulfated mucin, while in the common moorhen, secretion is neutral and carboxylate mucopolysaccarides. The natural secretion of choanal gland of these bird species confirms that these glands have no role in the digestion of food items. Moreover, these birds feed on meat; thereby, the digestion process occurs by secretion of preventriculus portion of the alimentary tract of the bird (McLelland, 1979), so their secretions of choanal gland in these bird species may help in lubrication of ingested food for ease of swelling process and provide an effective barrier against enzymatic acidic elements in contact with the buccal mucosal surface. In addition, we suggested that the choanal glands may share in detection the odoriferous molecules through dissolving in it as an olfactory stimulus.

\section{Conclusions}

The choana of the three studied bird species apparents adaptation to the olfaction process but also affects the movement of skeletal elements of the skull during the feeding process. We suggest that the different epithelium which appears within the choana and the natural of their gland secretions may be specialized for different functions. Thus, it is clear that we still have much to know about the structure and function of the choana in birds.

\section{Acknowledgements}

I would like to express our thanks to the microscopical unit in Zoology Dept. Faculty of Science, Assiut University, for their help in specimen preparations.
Funding

No funding sources

Availability of data and materials

No dataset was analyzed in the current study.

Authors' contributions

FM, AG, and NS designed and performed this work. All authors read and approved the final manuscript.

Ethics approval and consent to participate

The authors declare that this work is carried out within an appropriate ethical framework.

Consent for publication

Not applicable.

Competing interests

The authors declare that they have no competing interests.

\section{Publisher's Note}

Springer Nature remains neutral with regard to jurisdictional claims in published maps and institutional affiliations.

\section{Author details}

${ }^{1}$ Department of Zoology, Faculty of Science, Assiut University, Assiut, Egypt.

${ }^{2}$ Department of Zoology, Faculty of Science, AL-Azhar University, Assiut, Egypt.

Received: 2 November 2017 Accepted: 15 January 2018

Published online: 02 February 2018

\section{References}

Al-Zahaby, S. A., \& Elsheikh, E. H. (2014). Ultramorphological and histological studies on the tongue of the common kingfisher in relation to its feeding habit. The Journal of Basic and Applied Zoology, 67, 91-99.

Bancroft, J. D., \& Stevens, A. (1996). Theory and practice of histological techniques, (4th ed., ). Edinburgh: Churchill Livingstone.

Bang, B.G. and Wenzel, B.M. (1995). Nasal cavity and olfactory system. In: King, A S. and McLelland, J.( eds), Form and function in birds, (Vol. 3, Ch. 4 ,p.195225). Academic Press, San Diego.

Bout, R. G., \& Zweers, G. A. (2001). The role of cranial kinesis in birds. Comparative Biochemistry and Physiology, Part A, 131, 197-205.

El-Bakary, N. E. R. (2011). Surface morphology of the tongue of the hoopoe ( UpupaEpops). Journal of American Science, 7(1), 394-399.

El-Bakary, N. E. R. (2012). Scanning electron microscope study of the dorsal lingual surface of Halcyon smyrnensis (white breasted kingfisher). Global Veterinaria, 9(2), 192-195.

Erdogan, S., \& Iwasaki, S. (2014). Function- related morphological characteristics and specialized structures of the avian tongue. Annals of Anatomy, 196, 75-87.

Gadel-Rab, A. G., Shawki, N. A., \& Saber, S. A. A. (2012). Functional anatomy of the lingual apparatus of two bird species performing different feeding habits, PH. D. Thesis (). Assuit: Zoology Department, Faculty of Science, AL-Azhar University.

Gadel-Rab, A. G., Shawki, N. A., \& Saber, S. A. A. (2017). Morpho-functional adaptations of the lingual epithelium of two bird species which have different feeding habits. The Eygptian journal of Hospital Medicine, 69(3), 2115-2127.

Jackowiak, H., \& Godynicki, S. (2004). Light and scanning electron microscopic study of the tongue in the white tailed eagle (Haliaeetusalbicilla, Accipitridae, Aves). Annals of Anatomy, 187, 197-322.

Junqueira, L. C., \& Carneiro, J. (1980). Basic histology, Ch. 10 (3rd ed., pp. 190-192). Lange Medical Publications.

Kent, G. C., \& Carr, R. K. (2001). Comparative anatomy of the vertebrates, (9th ed., ). New York: McGraw-Hill.

Mahmoud, F. A., Gad-Rab, A. G., \& Shawki, N. A. (2017). Effect of different feeding behaviors on the lining epithelium of the roof of buccal cavity of two bird species. Egypt. J. Zool., 67, 175-190.

Mahmoud, F. A., Shawki, N. A., \& Abdeen, A. M. (2017). Biomechanics analysis of jaw musculature of the common kestrel (Falco tinnunculus) and the budgerigar (Melopsittacus undulates). Bio Bulletin, 3(1), 39-55. 
Mahmoud, F. A., Shawki, N. A., \& Wahba, M. T. (2009). Functional morphology of the feeding system of Falco tinnunculus, Master thesis (). Assuit: Zoology Department, Faculty of Science, Assuit University.

McLelland, J. (1979). Digestive system. In A. S. King, \& J. McLelland (Eds.), Form and function in birds, (vol. 3, pp. 69-181). London: Academic Press.

Rawal, U. M. (1968). Anatomy of the feeding apparatus of hoopoe- Upupa epops epops Linnaeus. Proceedings of the Indian Academy of Sciences Section B, 68(2), 79-90.

Schwenk, K. (2000). Feeding: Form, function and evolution in tetrapod vertebrates. San Diego: Academic Press.

Shah, S. W., \& Aziz, N. A. (2014). Morphology of the lingual apparatus of the Swiftlet, Aerodramus fuciphagus (Aves, Apodiformes, Apodidae). Journal of Microscopy and Ultrastructure, 2, 100-103.

Shawki, N. A., Abdeen, A. M., \& Mahmoud, F. A. (2016). Functional-morphological study of the oropharyngeal cavity and the tongue of the common kestrel, (Falco tinnunuculus), part l: The roof of the orophanyngeal cavity. IJRSZ., 1(3), 16-26.

Shawki, N. A., \& Ismail, A. I. (2006). Functional morphology of the lingual apparatus of the common moorhen, Gallinula choropus meridionali (Aves: Rallidae). 1- The lingual skeleton. Egypt. J. Zool., 46, 41-57.

\section{Submit your manuscript to a SpringerOpen ${ }^{\circ}$ journal and benefit from:}

- Convenient online submission

- Rigorous peer review

- Open access: articles freely available online

- High visibility within the field

- Retaining the copyright to your article

Submit your next manuscript at $\boldsymbol{s p r i n g e r o p e n . c o m ~}$ 